The use of an insect-proof package is a very important consideration in the connection with the shipment of all dried fruits, especially when packed in small cartons for retailing. A clean pack of ten becomes infested in the warehouse of the commission merchant or after it has reached the wholesale or the retail grocer, but no matter how it became infested, it reflects as much discredit upon the packer as if it had become infested before it left the packing house. Some recent. experiments conducted by the U. S. Department of Agriculture and published in Bulletin No. 235, June 24, 1915, show that an insectproof carton is both possible and inexpensive and has other important advantages besides those already stated.

Infested storehouses, warehouses, grocery stores, bakeries, etc., may be ricl of the beetles by a thorough fumigation with hydrocyanic acid gas at the rate of 3 ounces of sodium cyanide, and the proper proportions of sulphuric acid and water, to every 100 cubic feet of air space, or better if the place is fitted with a good steam-heating apparatus, the insects may be destroyed by maintaining a temperature of 125 degrees Fahrenheit for a period of several hours. Carbon bisulfid may also be used as a fumigant at the rate of one half pound to every 100 cubic feet of air space, but as it is highly inflammable and explosive when mixed with air it is very dangerous.

Cleanliness about the pitting, drying and packing sheds is very important in reducing the numbers of beetles which are likely to infest the fruit and the storage bins and warehouse should be thoroughly renovated before storing the new crop. Fruit from the previous year should be carefully inspected and removed, treated or destroyed if found infested.

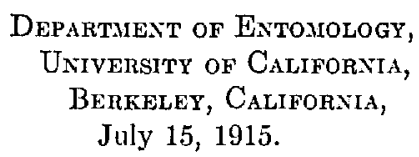

\title{
FUMIGATION METHOD FOR SACKED COTTON SEED
}

By W. E. Hinds, Entomologist, Auburn, Ala.

In connection with the administration of the boll weevil quarantine, it has frequently been necessary to fumigate considerable quantities of cotton seed originating in boll weevil infested territory to make it safe to allow shipments of such seed to points outside of the infested area. In the course of the boll weevil investigations more than ten years ago, it was found that carbon disulphide was the most practicable material for such fumigation work. Hydrocyanic acid gas has very 
little penetrative power in cotton seed. This material, on account of its texture, is extremely resistant to gas diffusion. Carbon disulphide vapor, however, penetrates quite readily through masses of cotton seed and is retained by the seed sufficiently long to make it a very effective protection against the transmission of living boll weevils in seed shipments.

The problem of application of the liquid to the seed was partially worked out and the method described in Farmers Bulletin 209 published in 1904. The method therein outlined involved practical difficulties in application on a large scale as the rapid evaporation of the liquid lowered the temperature to below the freezing point, thus freezing water that might be contained in the liquid disulphide and clogging the pipes.

The method herein described has been worked out in Alabama and used quite extensively in the treatment of cotton seed grown for planting purposes. With this method it has been found possible to treat 600 or more sacks per day with four men to do the work. Two men handle the application of the liquid, the method followed being shown quite clearly in the illustration. The other two men mark the sacks and pack them away after the treatment is given. Our method of dealing with seed for planting is to mark each treated sack with the initials of the man in charge of the fumigation work, the date of the treatment and serial number of the sack; e.g., A. B., 1-20-'15, No. 1, et seq. When shipping out fumigated seed, the grower could indicate upon the certificate accompanying the way-bill for the shipment, the numbers of the sacks included and this would constitute a positive identification and guard against the shipment of untreated seed. This method protects both the grower and buyer of the seed.

The apparatus consists essentially of a $3^{\prime \prime}$ air pump by which the liquid and vapor can be forced quickly into and through the seed. This is connected by pressure tubing with one branch of an ordinary ${ }_{4}^{1 \prime \prime} I$ such as is used in spraying work. On this branch there is a cutoff, also a regular spraying accessory. The other branch of the $Y$ has a similar cut-off and bears at its outer end a quarter turn with a metal cup at the top just large enough to hold, or so marked as to indicate accurately, the amount of liquid required for each sack. The $Y$ is connected with a piece of $\frac{1}{4}$ " galvanized gas pipe about $3 \frac{1}{2} \mathrm{ft}$. long, closed at the distal end with a metal plug sharpened to a point so that it will penetrate readily through the bagging and seed. For a distance of 18 inches back from this end the tubing is perforated in various dircctions and at distances of a few inches apart with a number of small openings through which the liquid and vapor are distributed so that it may diffuse through the sack in all directions. This type of 
tube is for use with the ordinary three-bushel sack. Almost any convenient receptacle may be used that will hold a quart or more of carbon disulphide and from which it may be readily poured into the metal cup. A one-gallon kerosene can is a convenient thing for this work but a different arrangement is shown in the illustration.

The method of procedure is as follows: Drive the perforated rod into the sack of seed to the proper place, close the cut-off on the cup side of the $Y$ and pour in the proper charge of liquid. Then open the cut-off and permit the liquid to run down into the pipe, closing the cut-off immediately thereafter and opening that on the air side of the $Y$. Two or three strokes from the air pump will be sufficient to force the liquid and gas into the seed and the perforated tube is then withdrawn. Care should be taken to have the cut-off closed on the liquid side of the $Y$ to prevent the air pressure forcing the liquid back into the face of the operator.

The treated sacks are closely stacked, preferably in a small room which is sufficiently tight so that the entire room may be given a regular treatment with disulphide as a final precaution. The seed is left stored in this room until shipped. This method of treatment has given entirely satisfactory results and is economical, both in the cost of apparatus and in the amount of liquid required. The method of treatment can, of course, be readily adapted to many other subjects beside sacked cotton seed. In treatment of cotton seed, our practice is to use one ounce of carbon disulphide per three-bushel sack of seed.

\section{NOTES ON AN APPARENT RELATION BETWEEN APHIDS AND FIRE BLIGHT (BACILLUS AMYLOVORUS)}

By J. H. MerriLL, Assistant Entomologist, Kansas Agricultural Experiment Station

Observations on this subject bave been carried on since the spring of 1913 in Doniphan County by the Department of Entomology of the Kansas Agricultural Experiment Station. During the spring of 1913 the aphids were noticed to be unusually abundant in nearly every orchard, especially on the Jonathan trees. They were found on the buds which had begun to swell but were not completely opened. Some of the fruit-growers, realizing that nothing but harm could result where so many sucking insects were present, sprayed with a contact insecticide to control them. Very few aphids were found in the orchards which had received a thorough dormant spraying with lime-sulphur.

Fire blight appeared later in the season in all of the orchards where 